\title{
Reliability of Power Spectral Analysis of Surface Electromyogram Recorded during Sustained Vastus Medialis Isometric Contraction in Assessment of Muscle Fatigability
}

\author{
Yuta Minoshima1, Yukihide Nishimura1 ${ }^{*}$, Hiroyuki Tsuboi', Hideyuki Satou1,

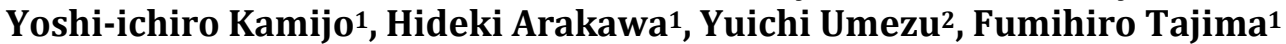 \\ ${ }^{1}$ Department of Rehabilitation Medicine, Wakayama Medical University, Wakayama, Japan \\ ${ }^{2}$ Department of Rehabilitation, Kokura Rehabilitation Hospital, Kitakyushu, Japan \\ Email: *yuki-n@wakayama-med.ac.jp
}

How to cite this paper: Minoshima, Y., Nishimura, Y., Tsuboi, H., Satou, H., Kamijo, Y.-I., Arakawa, H., Umezu, Y. and Tajima, F. (2017) Reliability of Power Spectral Analysis of Surface Electromyogram Recorded during Sustained Vastus Medialis Isometric Contraction in Assessment of Muscle Fatigability. Open Journal of Therapy and Rehabilitation, 5, 43-52. https://doi.org/10.4236/ojtr.2017.52005

Received: February 9, 2017

Accepted: May 7, 2017

Published: May 10, 2017

Copyright $\odot 2017$ by authors and Scientific Research Publishing Inc. This work is licensed under the Creative Commons Attribution International License (CC BY 4.0).

http://creativecommons.org/licenses/by/4.0/

\section{(c) (i) Open Access}

\begin{abstract}
The aim of this study was to determine the within-day and between-days reliability of surface electromyographic (EMG) power spectral analysis in assessing fatigability of the vastus medialis (VM) muscle during knee and hip flexion under constant load application. The subjects were 13 healthy adult men free of knee abnormalities. Surface EMG was recorded from vastus medialis obliquus (VMO) and vastus medialis longus (VML) during sustained isometric contractions at $60 \%$ of maximal voluntary contraction until exhaustion on the leg press machine (static leg press test). Linear regression analysis was applied to median frequency (MF) time series to calculate initial MF and MF slope. For VMO and VML, the initial MF showed moderate to high reliability, while the MF slope showed high reliability (Intraclass correlation coefficient (ICC) = initial MF: $0.63-0.92$, MF slope: $0.70-0.86$ ). The results demonstrated that spectral analysis of surface EMG recording during isometric VM muscle contraction has high within-day and between-days reliability in the assessment of fatigability of the VMO and VML.
\end{abstract}

\section{Keywords}

Vastus Medialis Oblique, Vastus Medialis Long, Muscle Fatigue, Electromyography, Isometric Contraction

\section{Introduction}

The strength of the quadriceps muscle correlates with locomotor function in pa- 
tients with osteoarthritis of the knee [1] [2]. Among the quadriceps muscles, the VM muscle is the major contributor to the stabilization and protection of the knee joint [3], and has been used as representative muscle of the quadriceps in investigations on muscle atrophy [4]. There are two components of VM; VMO and VML [5]. The VML, the proximal part of VM, inserts into the base of the patella, while the VMO, the distal part of the VM, originates mainly from the adductor magnus tendon and inserts at the medial margin of the patella. The quadriceps muscle becomes weak after injury to and reconstruction of the anterior cruciate ligament [6] [7] [8] [9], and weakness after the latter is associated with fatigue resistance [10].

The use of EMG power spectral analysis has demonstrated that muscle fatigue is associated with a shift in the MF toward lower values [11] [12] [13]. EMG power spectral analysis is also sometimes combined with histochemical analysis to determine muscle fiber type [14]. For example, Kupa et al. [14] reported that muscles with high percentages of fast glycolytic and fast oxidative glycolytic fibers exhibited greater MF initial value as well as greater reduction in MF over the course of contraction than those with higher concentrations of type I muscle fibers. Thus, EMG spectral parameters correlate with muscle fiber composition, and changes in MF have also been used as the marker of local muscle fatigability.

The unsupported trunk holding test (also known as "Sørensen back endurance test"), combined with EMG power spectral analysis, is a reliable method to measure the fatigue rate of back muscles [15]; the MF slope recorded during the test correlates significantly with the relative area of type I muscle fibers [16]. Recent studies described the relationships between age and sex with EMG power spectral analysis of back muscles during the trunk holding test [17] [18].

Previous studies used the dynamometer system (watching the dynamometer values) to measure the fatigability of the quadriceps muscle and reported either low [19] [20] [21] or moderate [22] [23] reliability of the MF slope. These results are probably related to the inappropriate application of constant load to the quadriceps during the dynamometer task load. It is desirable to apply a constant load to the quadriceps in the leg position holding task, similar to the trunk holding test, for accurate assessment of muscle fatigability. To our knowledge, there is no highly reliable method to measure the fatigability of VM. We assumed that an important factor in assessing the reliability of surface EMG power frequency analysis is to sustain posture, like in the trunk holding test. The aim of this study was to examine the within-day and between-days reliability of surface EMG power spectral analysis of the quadriceps during sustained quadriceps muscle isometric contraction, in the assessment of VM muscle fatigability.

\section{Methods}

\subsection{Subjects}

Thirteen healthy adult men participated in the present study. None of the subjects had history of knee symptoms and all were healthy at the time of the study. Subjects were asked to refrain from vigorous physical activity on the day before 
and the day of testing to avoid the effects of cumulative muscle fatigue. The study was approved by the Human Ethics Committee of Wakayama Medical University, and a written informed consent was obtained from each subject before participation.

\subsection{Task Application}

Knee extensor muscle strength was measured with the leg press machine (gym80, SYGNUM, Gelsenkirchen, Germany). After resting for 15 minutes in the sitting position, the subject was seated with right hip and knee flexion at $90^{\circ}$ on the leg press machine (Figure 1). The largest load that the subject could maintain with the knee at $90^{\circ}$ flexion for $5 \mathrm{sec}$ was defined as maximal voluntary contraction (MVC). The leg press machine was fixed to apply $60 \%$ of MVC with the right hip and knee at $90^{\circ}$ flexion. After resting for 15 minutes in the sitting position, the subject was instructed to press and sustain an isometric contraction leg press as long as possible (static leg press test; Figure 1). The test was terminated when the subject could no longer maintain the knee at $90^{\circ}$ flexion (defined as $>90^{\circ}$ flexion for $5 \mathrm{sec}$ ) despite strong verbal encouragement. The endurance time was recorded using a stopwatch and was taken as an indicator of knee extensors isometric endurance.

\subsection{EMG Signal Recording and Analysis}

The EMG activity was monitored during the static leg press test. Before attaching the electrodes, the area chosen for electrode placement was prepared by shaving (when appropriate) and cleaned with an alcohol swab. For this purpose,

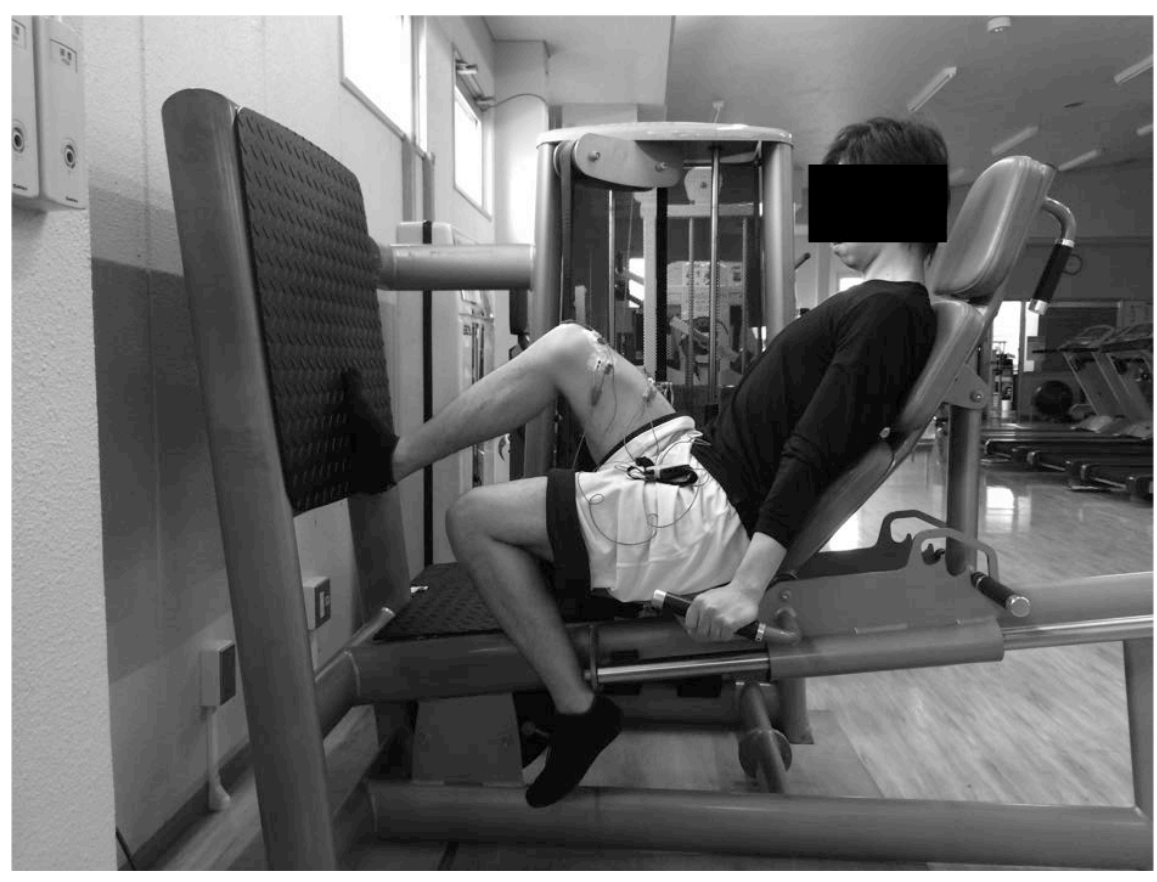

Figure 1. Photo showing body position during MVC and the static leg press test. The subject was asked to maintain $90^{\circ}$ flexion of the hip and knee and perform leg press on the wall plate, achieving persistent pushing power. 
two 10 -mm silver-silver chloride surface electrodes were placed $2 \mathrm{~cm}$ apart over VMO and VML. The active electrodes were placed over the VML based on SENIAM recommendations [24]; electrode placement on the VMO was at a distance of approximately $50 \mathrm{~mm}$ from the superior medial side of the patella along a line inclined to $50^{\circ}$ with respect to the anterior superior iliac spine [25]. The inter-electrode axis of the electrodes was aligned with the assumed direction of muscle fibers. The signal was bandpass filtered $(20-500 \mathrm{~Hz})$, amplified using MQ 16 (Marq-Medical of Denmark, Farum, Denmark), digitized using an A/D converter/Vital Recorder2 (Kissei Comtec, Nagano, Japan) and stored on a computer at $2000 \mathrm{~Hz}$ sampling rate. The MF indices were derived from the raw EMG signal as described above and plotted against time during the test using the Kinema Tracer Fast Fourier Transform spectrum analysis program (Kissei Comtec). Linear regression analysis was applied to the MF time series (MF as a function of time) to calculate the initial MF and MF slope. In a preliminary study, we confirmed that MF derived from the two muscles decreased linearly with the test time (Figure 2).

Thus, assessment of fatigability of knee extensor muscles during the leg load press test was evaluated using the above technique.

\subsection{Assessment of Reliability}

The study was an inter-rater reliability study. The within-day assessment consisted of two repetitions of the test package separated by an interval of $90 \mathrm{~min}$. The between-days assessment included performing the leg press load test after 7 days from the first test. Tests within the same day were completed with one electrode set, while the electrodes were replaced in the between-days tests.

\subsection{Statistical Analysis}

Data were expressed as mean \pm standard deviation (SD). ICC $(1,2)$ was used to express relative reliability of the measures [26]. ICC expresses the ratio of between-subject variance to within-subject variance and is a unitless value [26].

VMO

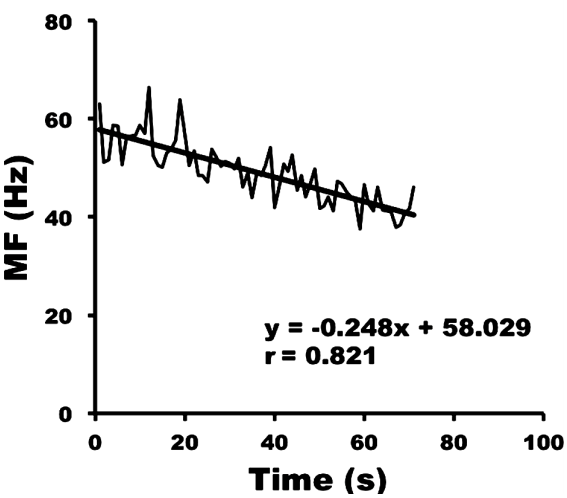

(a)
VML

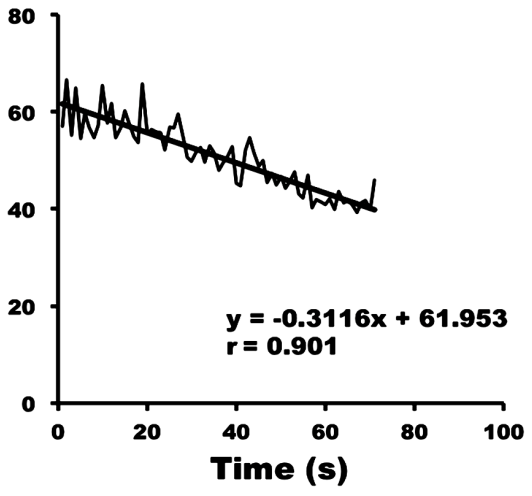

(b)

Figure 2. Changes in MF in the VMO (a) and VML (b). In a preliminary study, the MF derived from these muscles was shown to decrease linearly with test time. $\mathrm{P}<0.05$. 
Munro's descriptors of reliability coefficients were used to describe the degree of reliability: 0.00 to 0.25 -little, if any correlation; 0.26 to 0.49 -low correlation; 0.50 to $0.69-$ moderate correlation; 0.70 to 0.89 - high correlation and 0.90 to 1.00 -very high correlation [27].

Standard error of the measurement (SEM) was used to express absolute reliability of the measure [28]. SEM was calculated from the square root of the error variance (i.e., mean of standard deviations from within-day and between-days) and has the same unit as the tested variable. Smaller SEM values reflect more reliable measures [28]. The SEM was also expressed as percent of the mean value for the measure to allow comparison of absolute reliability between measurements $(\mathrm{SEM} /$ mean $\times 100 \%)$.

Before analyzing the correlation between MVC or initial MF and MF slopes, the normality of the data was checked using the Shapiro-Wilk test. A p value $<0.05$ denoted the presence of statistically significant difference. Statistical analysis was performed using the Statistical Package for Social Sciences software, version 23.0, for Windows (SPSS Inc., Chicago, IL).

\section{Results}

Characteristic of age was $25.6 \pm 2.7$ years, height was $174.7 \pm 5.7 \mathrm{~cm}$, body weight was $68.7 \pm 7.2 \mathrm{~kg}$, and body mass index was $22.5 \pm 2.4 \mathrm{~kg} / \mathrm{m}^{2}$ (Table 1 ).

All subjects completed three test sessions. The MVC was $91.1 \pm 14.5$ at the first time, $90.2 \pm 14.2$ at the second session, and $89.9 \pm 14.1$ at the third session. The endurance time, initial MF and MF slope recorded in these three sessions are listed in Table 2. Table 3 shows within-day and between-days reliabilities of all measurements. Both within-day and between-days reliabilities of the

Table 1. Anthropometric characteristics of the subjects.

\begin{tabular}{ccccc}
\hline & $\begin{array}{c}\text { Age } \\
(\text { year })\end{array}$ & $\begin{array}{c}\text { Height } \\
(\mathrm{cm})\end{array}$ & $\begin{array}{c}\text { Body weight } \\
(\mathrm{kg})\end{array}$ & $\begin{array}{c}\text { Body mass index } \\
\left(\mathrm{kg} / \mathrm{cm}^{2}\right)\end{array}$ \\
\hline Male $(\mathrm{n}=13)$, mean $\pm \mathrm{SD}$ & $25.6 \pm 2.7$ & $174.7 \pm 5.7$ & $68.7 \pm 7.2$ & $22.5 \pm 2.4$ \\
\hline
\end{tabular}

Table 2. Mean data of the MVC, endurance time, initial MF and MF slope recorded at the three sessions.

\begin{tabular}{cccc}
\hline & First session & Second session & Third session \\
\hline MVC (kg) & $91.1 \pm 14.5$ & $90.2 \pm 14.2$ & $89.9 \pm 14.1$ \\
Endurance Time (sec) & $54.8 \pm 10.0$ & $56.1 \pm 9.4$ & $60.6 \pm 13.7$ \\
Initial MF (Hz) & & & \\
VMO & $61.3 \pm 10.0$ & $61.7 \pm 9.1$ & $67.1 \pm 12.9$ \\
VML & $68.7 \pm 11.0$ & $66.1 \pm 10.4$ & $69.6 \pm 9.8$ \\
MF slope (Hz/sec) & & & \\
VMO & $-0.374 \pm 0.119$ & $-0.351 \pm 0.119$ & $-0.398 \pm 0.159$ \\
VML & $-0.415 \pm 0.210$ & $-0.316 \pm 0.184$ & $-0.383 \pm 0.163$ \\
\hline
\end{tabular}

Data are mean $\pm \mathrm{SD}$ 
Table 3. Within-day and between-days reliabilities of MVC, endurance time, initial MF and MF slope.

\begin{tabular}{ccccc}
\hline & \multicolumn{2}{c}{ Within-day } & \multicolumn{2}{c}{ Between-days } \\
\hline & ICC (95\% CI) & SEM (\%) & ICC (95\% CI) & SEM (\%) \\
\hline MVC (kg) & $0.96(0.92-0.96)$ & $0.89(96.0 \%)$ & $0.96(0.88-0.99)$ & $1.10(89.3 \%)$ \\
Endurance time (sec) & $0.70(0.27-0.90)$ & $2.10(170 \%)$ & $0.70(0.22-0.90)$ & $2.29(39.7 \%)$ \\
Initial MF (Hz) & & & & \\
VMO & $0.88(0.66-0.96)$ & $1.32(315.7 \%)$ & $0.63(0.15-0.87)$ & $2.51(43.3 \%)$ \\
VML & $0.92(0.69-0.98)$ & $1.01(38.7 \%)$ & $0.92(0.77-0.96)$ & $1.17(128.1 \%)$ \\
MF slope (Hz/sec) & & & & \\
VMO & $0.86(0.67-0.96)$ & $0.015(66.7 \%)$ & $0.70(0.28-0.90)$ & $0.03(124.0 \%)$ \\
VML & $0.78(0.20-0.94)$ & $0.029(29.5 \%)$ & $0.82(0.53-0.94)$ & $0.03(96.3 \%)$ \\
\hline
\end{tabular}

Data are mean \pm SD.

MVC were 0.96, categorized into "very high correlation", with limited 95\% CI values, suggesting high accuracy of our measurements. However, both reliabilities of endurance time were not that high, 0.70 , and the $95 \%$ CIs were broader than those of MVC, though still categorized as "high correlation". On the other hand, the reliabilities of the initial MF and MF slope indicated mostly high or very high correlations. For VML, both within-day and between-days reliabilities of the initial MF and MF slope were categorized as "high or very high". For the VMO, within-day reliabilities were also categorized as "high", though the between-days reliabilities were less than high; 0.63 (moderate) for the initial MF and 0.70 (high) for the MF slope, and the $95 \%$ CIs were broader than those of the VML.

\section{Discussion}

The main finding of this study was the reliability of the within-day and between-days of MF and MF slope surface parameters of EMG power spectral analysis derived from the VMO and VML and recorded during the leg load press test. The results suggest that EMG power spectral analysis of the VM muscle during the leg load press test is highly reliable method for assessment of VM muscle fatigability.

The present study demonstrated significant reliability of the initial MF and MF slope of the VMO and VML in the assessment of VM muscle fatigability; the main reason was probably related to the use of larger submaximal loads for the quadriceps compared with those applied in previous studies [19] [20] [21] [22] [23]. The present study did not use a visual biofeedback system; the subjects performed a simple task designed to keep the leg at identical position and the subjects managed to achieve quadriceps muscle isometric contraction. EMG power spectral analysis during sustained quadriceps muscle isometric contraction should be one of the most important techniques, and thus the present study demonstrated the high reliability of the MF slope of the VMO and VML. 
With regard to the relevance of the parameters of the EMG power spectral analysis, previous studies suggested that the MF slope during fatigue reflects the changes in action potential propagation of individual muscle fibers, which is the result of the associated accumulation of metabolic by-products (lactate and extracellular $\mathrm{K}+$ ) [29] [30]. EMG power spectral analysis is sometimes combined with histochemical analysis to determine the muscle fiber type. In particular, muscles with larger percentages of fast glycolytic and fast oxidative glycolytic fibers exhibit more rapid reduction of MF over the course of contraction than those with higher concentrations of type I muscle fibers. Kupa et al. [14] indicated that these properties allow the use of surface EMG techniques to obtain noninvasive electrophysiological "muscle biopsy" and to estimate muscle fiber composition. Changes in MF have also been used as a marker of local muscle fatigability; the MF slopes of the VMO and VML continually decreased during isometric contraction.

One limitations of this study is a small sample size. Future studies should examine whether the pattern of results observed here are found with a larger sample, based on a priori sample size calculations. Another limitation of this study is examined only healthy adult men. In future, also the reliability of VM muscle fatigability is needed for women.

\section{Conclusion}

Surface EMG recording and power spectral analysis during sustained quadriceps muscle isometric contraction showed high within-day and between-days reliability in the assessment of fatigability of the VMO and VML.

\section{Acknowledgements}

We thank Hideaki Tanina and Ryo Koyanagi for the technical assistance. We also thank Dr. Faiq G. Issa (www.word-medex.com.au) for the careful reading and editing of the manuscript.

\section{References}

[1] Hurley, M.V. (1999) The Role of Muscle Weakness in the Pathogenesis of Osteoarthritis. Rheumatic Disease Clinics of North America, 25, 283-298.

http://www.sciencedirect.com/science/article/pii/S0889857X05700685 https://doi.org/10.1016/S0889-857X(05)70068-5

[2] McCarthy, C.J. and Oldman, J.A. (2004) The Reliability, Validly and Responsiveness of an Aggregated Locomotor Function (ALF) Score in Patients with Osteoarthritis of the Knee. Rheumatology (Oxford), 43, 514-517. https://doi.org/10.1093/rheumatology/keh081

[3] Smillie, I.S. (1949) The Quadriceps in Relation to Recovery from Injuries of the Knee-Joint. Physiotherapy, 35, 53-57. http://europepmc.org/abstract/med/18149874

[4] Fox, T.A. (1975) Dysplasia of the Quadriceps Mechanism: Hypoplasia of the Vastus Medialismuscle as Related to the Hypermobile Patella Syndrome. Surgical Clinics of North America, 55, 199-226. http://www.sciencedirect.com/science/article/pii/S0039610916405426 
[5] Lieb, F.J. and Perry, J. (1968) Quadriceps Function. An Anatomical and Mechanical Study Using Amputated Limbs. Journal of Bone \& Joint Surgery-American Volume, 50, 1535-1548. https://doi.org/10.2106/00004623-196850080-00003

[6] Lieber, R.L., Silva, P.D. and Daniel, D.M. (1996) Equal Effectiveness of Electrical and Volitional Strength Training for Quadriceps Femoris Muscles after Anterior Cruciate Ligament Surgery. Journal of Orthopaedic Research, 14, 131-138. http://onlinelibrary.wiley.com/doi/10.1002/jor.1100140121/full https://doi.org/10.1002/jor.1100140121

[7] McHugh, M.P., Spitz, A.L., Lorei, M.P., Nicholas, S.J., Hershman, E.B. and Gleim, G.W. (1994) Effects of Anterior Cruciate Ligament Deficiency on Economy of Walking and Jogging. Journal of Orthopaedic Research, 12, 592-597.

http://onlinelibrary.wiley.com/doi/10.1002/jor.1100120416/full https://doi.org/10.1002/jor.1100120416

[8] McHugh, M.P., Tyler, T.F., Gleim, G.W. and Nicholas, S.J. (1998) Preoperative Indicators of Motion Loss and Weakness Following Anterior Cruciate Ligament Reconstruction. Journal of Orthopaedic \& Sports Physical Therapy, 27, 407-411. http://www.jospt.org/doi/abs/10.2519/jospt.1998.27.6.407? code=jospt-site https://doi.org/10.2519/jospt.1998.27.6.407

[9] Snyder-Mackler, L., Binder-Macleod, S.A. and Williams, P.R. (1993) Fatigability of Human Quadriceps Femoris Following Anterior Cruciate Ligament Reconstruction. Medicine \& Science in Sports \& Exercise, 25, 783-789.

http://europepmc.org/abstract/med/8350699 https://doi.org/10.1249/00005768-199307000-00005

[10] McHugh, M.P., Tyler, T.F., Nicholas, S.J., Browne, M.G. and Gleim, G.W. (2001) Electromyographic Analysis of Quadriceps Fatigue after Anterior Cruciate Ligament Reconstruction. Journal of Orthopaedic \& Sports Physical Therapy, 31, 25-32. http://www.jospt.org/doi/abs/10.2519/jospt.2001.31.1.25 https://doi.org/10.2519/jospt.2001.31.1.25

[11] De Luca, C.J. (1984) Myoelectrical Manifestations of Localized Muscular Fatigue in Humans. Critical Reviews in Biomedical Engineering, 11, 251-279. http://europepmc.org/abstract/med/6391814

[12] Merletti, R., Knaflitz, M. and De Luca, C.J. (1990) Myoelectric Manifestations of Fatigue in Voluntary and Electrically Elicited Contractions. Journal of Applied Physiology, 69, 1810-1820. http://jap.physiology.org/content/69/5/1810.short

[13] Umezu, Y., Shiba, N., Tajima, F., Mizushima, T., Okawa, H., Ogata, H., Nagata, K. and Basford, J.R. (2003) Muscle Endurance and Power Spectrum of the Triceps Brachii in Wheelchair Marathon Racers with Paraplegia. Spinal Cord, 41, 511-515. http://www.nature.com/sc/journal/v41/n9/abs/3101495a.html https://doi.org/10.1038/sj.sc.3101495

[14] Kupa, E.J., Roy, S.H., Kandarian, S.C. and De Luca, C.J. (1995) Effects of Muscle Fiber Type and Size on EMG Median Frequency and Conduction Velocity. Journal of Applied Physiology, 79, 23-32. http://jap.physiology.org/content/79/1/23.short

[15] Ng, J.K. and Richardson, C.A. (1996) Reliability of Electromyographic Power Spectral Analysis of Back Muscle Endurance in Healthy Subjects. Archives of Physical Medicine and Rehabilitation, 77, 259-264.

http://www.sciencedirect.com/science/article/pii/S0003999396901082 https://doi.org/10.1016/S0003-9993(96)90108-2

[16] Mannion, A.F., Dumas, G.A., Stevenson, J.M. and Cooper, R.G. (1998) The Influence of Muscle Fiber Size and Type Distribution on Electromyographic Measures of Back Muscle Fatigability. Spine, 23, 576-584. 
https://doi.org/10.1097/00007632-199803010-00010

[17] Tanina, H., Nishimura, Y., Tsuboi, H., Sakata, T., Nakamura, T., Murata, K.Y., Arakawa, H., Umezu, Y. and Tajima, F. (2017) Fatigue-Related Differences in Erector Spinae between Prepubertal Children and Young Adults Using Surface Electromyographic Power Spectral Analysis. Journal of Back and Musculoskeletal Rehabilitation, 30, 1-9.

[18] Tsuboi, H., Nishimura, Y., Sakata, T., Ohko, H., Tanina, H., Kouda, K., Nakamura, T., Umezu, Y. and Tajima, F. (2013) Age-Related Sex Differences in Erector Spinae Muscle Endurance Using Surface Electromyographic Power Spectral Analysis in Healthy Humans. The Spine Journal, 13, 1928-1933.

http://www.sciencedirect.com/science/article/pii/S1529943013007468 https://doi.org/10.1016/j.spinee.2013.06.060

[19] Kollmitzer, J., Ebenbichier, G.R. and Kopf, A. (1999) Reliability of Surface Electromyographic Measurements. Clinical Neurophysiology, 110, 725-734.

http://www.sciencedirect.com/science/article/pii/S1388245798000509 https://doi.org/10.1016/S1388-2457(98)00050-9

[20] McCarthy, C.J., Callaghan, M.J. and Oldham, J.A. (2008) The Reliability of Isometric Strength and Fatigue Measures in Patients with Knee Osteoarthritis. Manual Therapy, 13, 159-164. https://doi.org/10.1016/j.math.2006.12.003 http://www.sciencedirect.com/science/article/pii/S1356689X06001792

[21] Zech, A., Witte, K. and Pfeifer, K. (2008) Reliability and Performance-Dependent Variations of Muscle Function Variables during Isometric Knee Extension. Journal of Electromyography and Kinesiology, 18, 262-269.

http://www.sciencedirect.com/science/article/pii/S1050641106001258 https://doi.org/10.1016/j.jelekin.2006.08.013

[22] Callaghan, M.J., McCarthy, C.J. and Oldham, J.A. (2009) The Reliability of Surface Electromyography to Assess Quadriceps Fatigue during Multi Joint Tasks in Healthy and Painful Knees. Journal of Electromyography and Kinesiology, 19, 172 180. http://www.sciencedirect.com/science/article/pii/S105064110700079X https://doi.org/10.1016/j.jelekin.2007.05.004

[23] Mathur, S., Eng, J.J. and Maclntyre, D.L. (2005) Reliability of Surface EMG during Sustained Contractions of the Quadriceps. Journal of Electromyography and Kinesiology, 15, 102-110. https://doi.org/10.1016/j.jelekin.2004.06.003 http://www.sciencedirect.com/science/article/pii/S1050641104000574

[24] Hermens, H.J., Freriks, B., Disselhorst-Klug, C. and Rau, G. (2000) Development of Recommendations for SEMG Sensors and Sensor Placement Procedures. Journal of Electromyography and Kinesiology, 10, 361-374.

http://www.sciencedirect.com/science/article/pii/S1050641100000274 https://doi.org/10.1016/s1050-6411(00)00027-4

[25] Rainoldi, A., Bullock-Saxton, J.E., Cavarretta, F. and Hogan, N. (2001) Repeatability of Maximal Voluntary Force and of Surface EMG Variables during Voluntary Isometric Contraction of Quadriceps Muscles in Healthy Subjects. Journal of Electromyography and Kinesiology, 11, 425-438.

http://www.sciencedirect.com/science/article/pii/S1050641101000220 https://doi.org/10.1016/S1050-6411(01)00022-0

[26] Thorstensson, A., Grimby, G. and Karlsson, J. (1976) Force-Velocity Relations and Fiber Composition in Human Knee Extensor Muscles. Journal of Applied Physiology, 40, 12-16. http://jap.physiology.org/content/40/1/12.short

[27] Newell, K.M. and Carlton, L.G. (1985) On the Relationship between Peak Force and Peak Force Variability in Isometric Tasks. Journal of Motor Behavior, 17, 230-241. 
http://www.tandfonline.com/doi/abs/10.1080/00222895.1985.10735346 https://doi.org/10.1080/00222895.1985.10735346

[28] Domholdt, E. (2000) Physical Therapy Research: Principles and Applications, 2nd Edition, WB Saunders Co., Philadelophia.

[29] Brody, L.R., Pollock, M.T., Roy, S.H., De Luca, C.J. and Celli, B. (1991) pH-Induced Effects on Median Frequency and Conduction Velocity of the Myoelectric Signal. Journal of Applied Physiology, 71, 1878-1885.

http://jap.physiology.org/content/71/5/1878

[30] Vestergaard-Poulsen, P., Thomsen, C., Sinkjaer, T. and Henriksen, O. (1995) Simultaneous 31P-NMR Spectroscopy and EMG in Exercising and Recovering Human Skeletal Muscle: A Correlation Study. Journal of Applied Physiology, 79, 14691478. http://jap.physiology.org/content/79/5/1469.short

Submit or recommend next manuscript to SCIRP and we will provide best service for you:

Accepting pre-submission inquiries through Email, Facebook, LinkedIn, Twitter, etc. A wide selection of journals (inclusive of 9 subjects, more than 200 journals)

Providing 24-hour high-quality service

User-friendly online submission system

Fair and swift peer-review system

Efficient typesetting and proofreading procedure

Display of the result of downloads and visits, as well as the number of cited articles Maximum dissemination of your research work

Submit your manuscript at: http://papersubmission.scirp.org/

Or contact ojtr@scirp.org 